\title{
IRNSS/NavIC: Indigenous Indian Satellite Navigation Programme
}

Soma $\mathbf{P}$

Ex. Project Director (Ground Segment), IRNSS, ISRO

DOI: https://doi.org/10.34293/acsjse.v1i1.2

\begin{abstract}
India has a vibrant space programme, and over years has successfully operationalized communication and remote sensing satellites for the benefit of the country. In order to achieve selfreliance in satellite-based navigation service over Indian region, Indian Space Research Organization (ISRO) has initiated the NavIC (Navigation with Indian Constellation) Programme. NavIC is developed to give PNT (Position, Navigation and Time) services for users over Indian region and its neighbourhood with positional accuracy of $20 \mathrm{~m}$ and 10 Nano seconds time accuracy. It provides navigation services to Indian landmass and also it extends its service to 1500 $\mathrm{km}$ beyond the geopolitical boundary. This paper provides the overview about the IRNSS and its salient features.
\end{abstract}

\section{INTRODUCTION}

Navigation is the process of scheduling and controlling the land vehicle, ship and aircraft movement. Several navigational procedures have evolved over the time. With the beginning of the space age in 1957, Satellites are used for accurate and reliable global navigation and many countries are involved in developing satellite based navigation systems capable of serving on a global or regional scale. The current scenario of navigation satellite system is provided in table 1. Global Positioning System belongs to USA has been the forerunner and has been operational for over 20 years with its numerous applications in the civilian and military domains.

Table 1: Navigation Satellite Systems

\begin{tabular}{|c|c|c|c|c|c|c|}
\hline $\begin{array}{c}\text { Satellite } \\
\text { Constellation }\end{array}$ & $\begin{array}{c}\text { GPS } \\
\text { (USA) }\end{array}$ & $\begin{array}{c}\text { GALILEO } \\
\text { (Europe) }\end{array}$ & $\begin{array}{c}\text { GLONASS } \\
\text { (Russia) }\end{array}$ & $\begin{array}{c}\text { BEIDOU } \\
\text { China }\end{array}$ & $\begin{array}{c}\text { NavIC } \\
\text { (India) }\end{array}$ & $\begin{array}{c}\text { QZSS } \\
\text { (Japan) }\end{array}$ \\
\hline $\begin{array}{c}\text { Tumber of } \\
\text { satellites required } \\
\text { (GNSS) }\end{array}$ & 27 & 30 & 24 & 35 & Regional & Regional \\
\hline $\begin{array}{c}\text { Number of } \\
\text { satellites required } \\
\text { (RNSS) }\end{array}$ & - & - & - & 14 & 7 & 4 to 7 \\
\hline $\begin{array}{c}\text { No of Operational } \\
\text { Satellites }\end{array}$ & 31 & 10 & 29 & 17 & 7 & 1 \\
\hline $\begin{array}{c}\text { Condition of } \\
\text { Implementation }\end{array}$ & Operational & $\begin{array}{c}\text { Under } \\
\text { Implementation }\end{array}$ & Operational & Operational & $\begin{array}{c}\text { Under Testing \& } \\
\text { Operationalization }\end{array}$ & Implementation \\
\hline $\begin{array}{c}\text { Stable } \\
\text { Service Record }\end{array}$ & 20 Years & - & 2 Years & 1 Year & - & - \\
\hline PDOP & 1.96 & - & 4.39 & 3.48 & 3.5 & - \\
\hline
\end{tabular}


India has a vibrant space programme, and over years has successfully operationalized communication and remote sensing satellites for the benefit of the country. In order to achieve self reliance in satellite based navigation service over Indian region, Indian Space Research Organization (ISRO) has initiated the NavIC (Navigation with Indian Constellation) Programme. NavIC is developed to give PNT (Position, Navigation and Time) services for users over Indian region and its neighbourhood with positional accuracy of $20 \mathrm{~m}$ and 10 Nano seconds time accuracy. It provides navigation services to Indian landmass and also it extends its service to $1500 \mathrm{~km}$ beyond the geopolitical boundary. This paper provides the overview about the IRNSS and its salient features.

\section{IRNSS ARCHITECTURE}

IRNSS system comprises of three segments, like Ground, User and Space Segment as illustrated in figure $1[1]$.

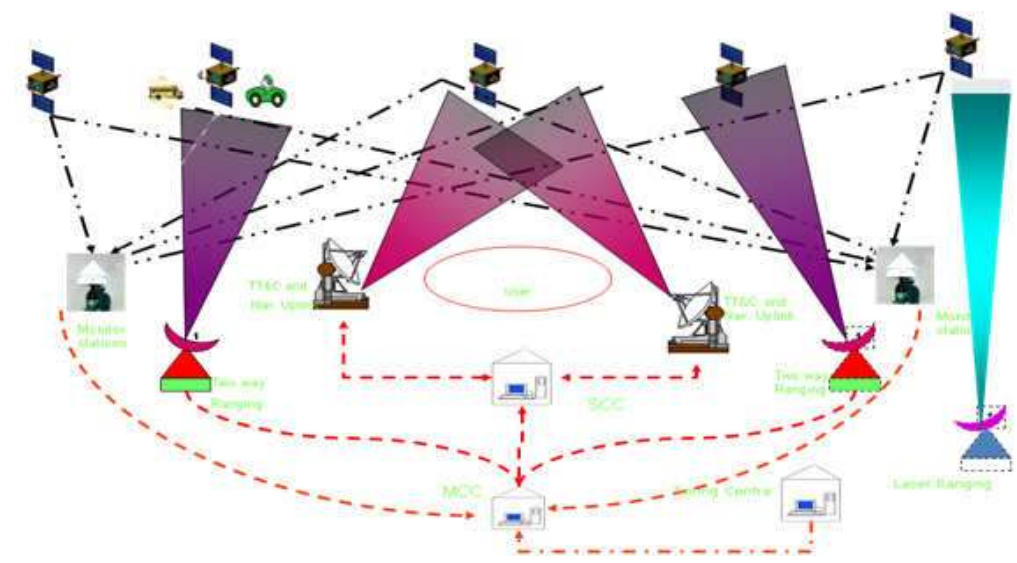

Figure 1: IRNSS Architecture

\section{Space Segment}

This segment is having the constellation of 7 satellites at $36000 \mathrm{~km}$ altitude. Three of these satellites are located in the geostationary orbit at $32.5 \mathrm{deg}$ E, $83 \mathrm{deg}$ E and $131.5 \mathrm{deg}$ E. Other 4 satellites are placed in geosynchronous orbit with an equatorial crossing at $55 \mathrm{deg} \mathrm{E}$ and $111.75 \mathrm{deg} \mathrm{E}$ with an inclination of $29 \mathrm{deg}$. The constellation is so chosen to provide continuous regional coverage for PNT services over the defined region. All the NavIC satellites are designed, built, launched and operated by ISRO. IRNSS satellites have a lift off mass of $1425 \mathrm{~kg}$ and dry mass of $600 \mathrm{~kg}$. The life span of satellite is 7-10 years. All NavIC satellites are launched by PSLV from SHAR, Sriharikota. The IRNSS satellite Centre has Ranging Payload and Navigation Payload. IRNSS - 1A which is shown in Figure 2. For laser ranging it is having the corner cube retro reflectors [1,2]. 


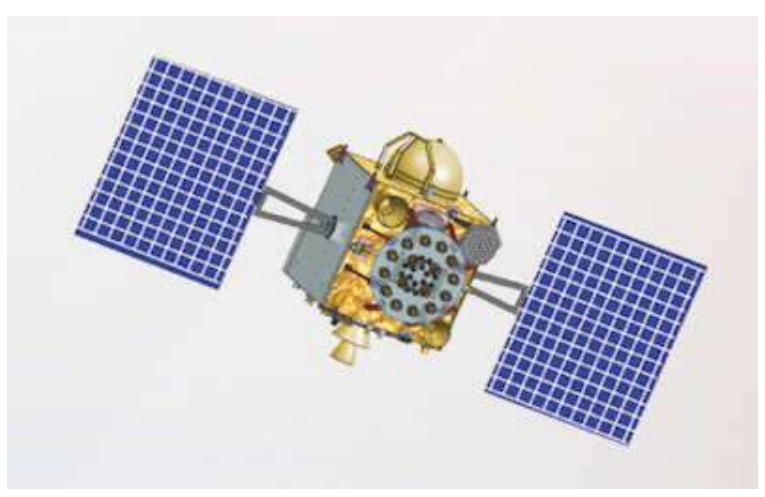

Figure 2: IRNSS - 1A Satellite

\section{Navigation Payload}

The rubidium atomic frequency standard is the heart of the navigation payload that generates highly stable and accurate timing signals. The navigation transponder with signal generation unit generates the navigation signal in both the L5 and S band frequencies.

\section{Ranging Payload}

The ranging payload is used for the CDMA ranging which is essential for precise satellite ranging. Corner cube reflectors are used in laser ranging to get sub meter level accuracy in satellite position.

\section{IRNSS Constellation and Coverage}

The IRNSS Constellation details are given in table 2 .

Table 2: IRNSS Constellation Details

\begin{tabular}{|c|c|c|c|c|c|}
\hline S. No & $\begin{array}{c}\text { NavIC } \\
\text { Satellite }\end{array}$ & Longitude & Inclination & RAAN & Date of Launch \\
\hline 1. & 1A & $55.0 \mathrm{deg}$ & $29 \mathrm{deg}(+/-2)$ & $135 \mathrm{deg}$ & July 1, 2013 \\
\hline 2. & 1B & $55.0 \mathrm{deg}$ & $29 \mathrm{deg}(+/-2)$ & $310 \mathrm{deg}$ & April 4, 2014 \\
\hline 3. & $1 \mathrm{C}$ & $83.0 \mathrm{deg}$ & $0 \mathrm{deg}$ & $274 \mathrm{deg}$ & October 15, 2014 \\
\hline 4. & 1D & $111.75 \mathrm{deg}$ & $29 \mathrm{deg}(+/-2)$ & $135 \mathrm{deg}$ & March 27, 2015 \\
\hline 5. & 1E & $111.75 \mathrm{deg}$ & $29 \mathrm{deg}(+/-2)$ & $310 \mathrm{deg}$ & January 20, 2016 \\
\hline 6. & 1F & $32.5 \mathrm{deg}$ & $+/-5 \mathrm{deg}$ & $270 \mathrm{deg}$ & March 10, 2016 \\
\hline 7. & $1 \mathrm{G}$ & $131.5 \mathrm{deg}$ & $+/-5 \mathrm{deg}$ & $270 \mathrm{deg}$ & April 28, 2016 \\
\hline
\end{tabular}

The coverage of this constellation for providing navigation information is shown in Figure 3. The NavIC satellites broadcast navigation signals in L5 and S bands. The basic services offered are Standard Position Service and Restricted Service. It provides services to the area covering India and $1500 \mathrm{Km}$ around Indian land mass. The L5 and S band frequencies are centered at 1176.42 MHz and 2492.048 MHz respectively. 


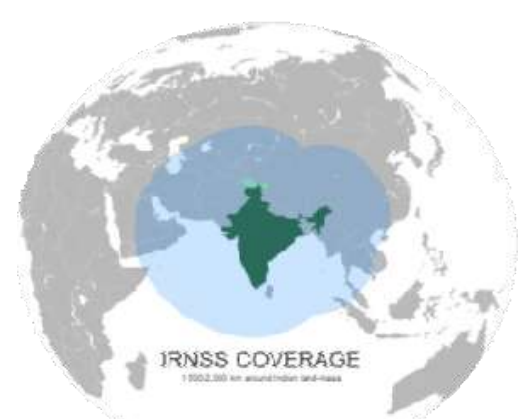

Figure 3: IRNSS Coverage

\section{IRNSS Signals and Services}

The IRNSS signals and services are given in Table 3.

Table 3: IRNSS Services

\begin{tabular}{|c|c|c|c|c|}
\hline S. No & Service Type & Signals & $\begin{array}{c}\text { Frequency } \\
\text { Band }(\mathbf{B W})\end{array}$ & Carrier Frequency \\
\hline 1. & Standard Positioning Service & $\begin{array}{l}1.023 \\
\text { Mcps }\end{array}$ & L5 $(24 \mathrm{MHz})$ & \begin{tabular}{l}
$1176.45 \mathrm{MHz}$ \\
\cline { 4 - 5 }
\end{tabular} \\
\hline 2. & Precise Positioning Service & $\begin{array}{l}10.23 \\
\text { Mcps }\end{array}$ & L5 and S & $\begin{array}{c}1176.45 \mathrm{MHz} \text { and } \\
2492.028 \mathrm{MHz}\end{array}$ \\
\hline 3. & $\begin{array}{c}\text { Restricted Services for Special } \\
\text { Users }\end{array}$ & $\begin{array}{l}10.23 \\
\text { Mcps }\end{array}$ & L5 & $1176.45 \mathrm{MHz}$ \\
\hline
\end{tabular}

\section{GROUND SEGMENT}

NavIC ground segment which is shown in Figure 4, includes the satellite control facility located at Hassan and Bhopal and NavIC Navigation Centre. It includes range and reliability monitoring stations, CDMA ranging stations and timing centre. And also the facility comprises of NavIC TTC and station for Uplink.

The Navigation control facility comprises of seventeen Indian Range and Integrity Monitoring Stations at different parts in the country. Two Navigation control facilities with attendant navigation software and located at Bangalore and Lucknow are responsible for finding the orbital parameter for each of the satellite, generating navigation messages and transmitting the messages to the spacecrafts through the satellite control center. The data storage and processing facilities available at Indian Navigation Centre enables systematic storage and processing of data.

Data communication network interlinks all the work centres for data transfer. NavIC Network Time is derived from atomic clocks at Indian Navigation Center, Bangalore. Four CDMA ranging stations provide the two way ranging data for the NavIC satellites. The ground segment is used for generation of navigation parameters and transmission, control of satellites, time keeping, ranging, monitoring, mission control and various other activities like maintenance and operation of the IRNSS constellation. 


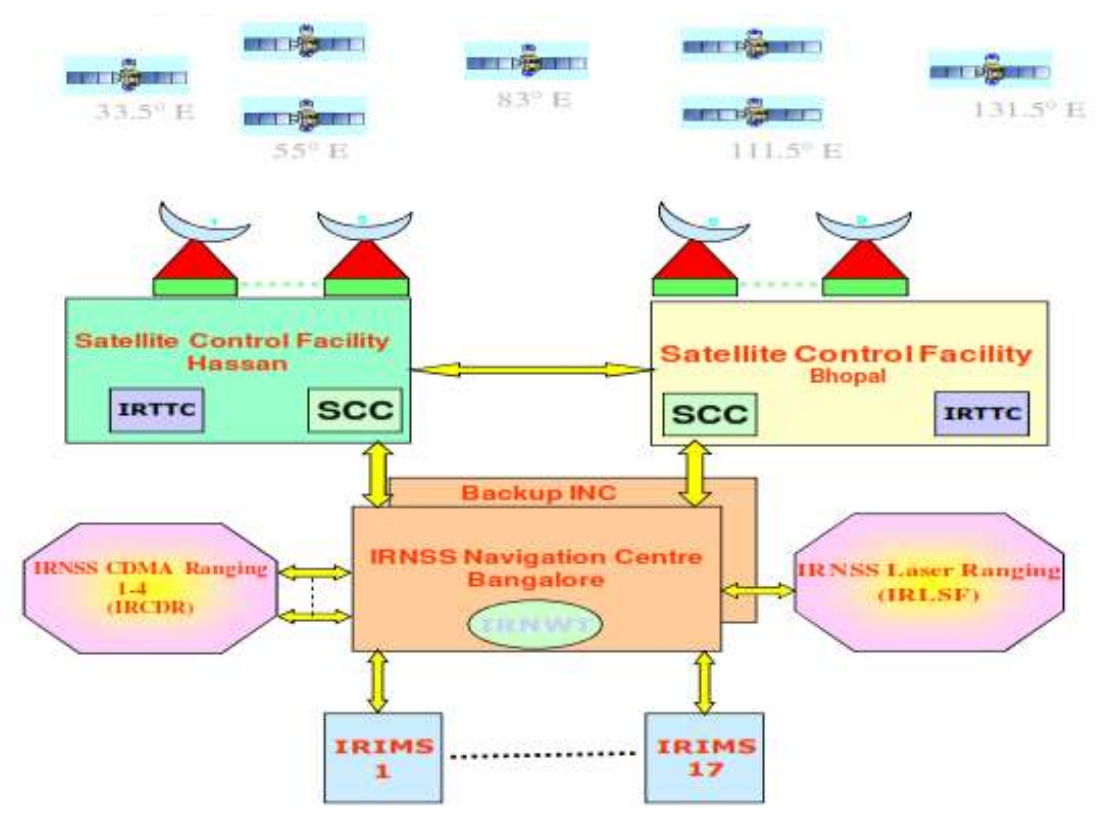

Figure 4: IRNSS Ground Segment

\section{User Segment}

It consists of NavIC receivers operating in either L5 band or S band frequency and L5 $\& \mathrm{~S}$ band (Dual frequency) is shown in figure 5. The SPS (Civilian Users) and RS (Authorized Users) signals received by both Single and dual frequency receivers.

\section{User Segment}

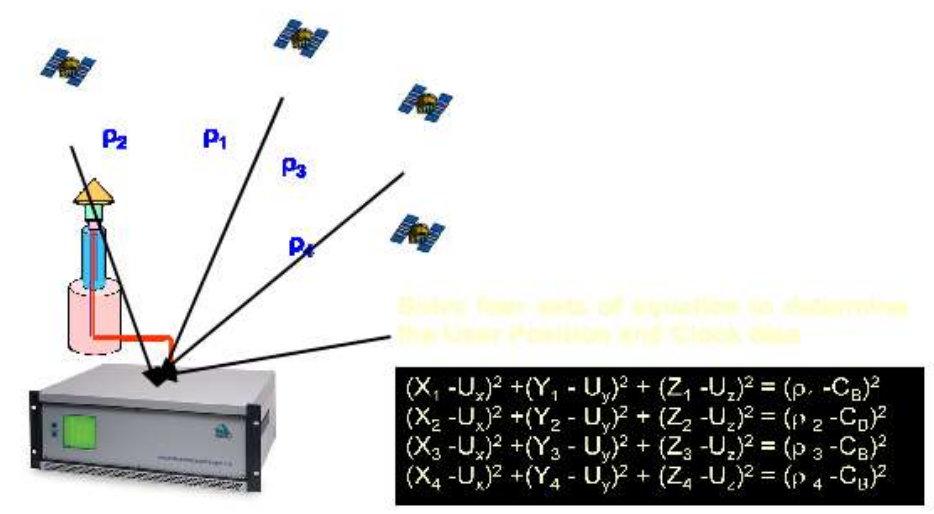

Figure 5: IRNSS User Segment

Several commercial agencies are occupied in the design and development of NavIC user receivers. The positional accuracy of Global Navigation Satellite Systems is limited by Ionospheric, Clock and Ephemerides errors. While most of the GNSS systems use the L band signals [3], IRNSS uses $\mathrm{S}$ band signals in addition to $\mathrm{L}$ band signals which have low background noise levels and experiences less Ionospheric delays when compared to L band signals. 


\section{Testing Signal in SPaCe}

After every satellite launch, elaborate exercises are carried out to test the payload performance and ensure SIS quality. Independent exercises are carried out to determine the accuracy of position determination of NavIC satellite with the help of International Laser Ranging network. In an independent analysis made by O. Montenbruck [4] concludes that 'signal in space range errors are at a level of five meters, which is reliable with the exactness evaluation given in navigational message'. Proof of concept was demonstrated in achieving the positional accuracy with four satellites less than 20 meters [5].

Several user receivers are deployed in the region and the performance of the system for PNT services were studied and reported at the IRNSS user meet held in 2015. Presently the constellation is being tested and evaluated for its performance

\section{CONCLUSION}

India has successfully designed, built and launched the IRNSS system. Fully operational ground segment is in place. Elaborate testing of the system is in progress and the system is expected to be operational soon. IRNSS signals are compatible and inter-operable with all other GNSS systems.

The development of IRNSS has provided the much needed self-reliance to the Indian users in the GNSS technology. This will provide benefits to many users such as smart transportation in the land, air and sea and apart from that it will be useful for telecommunication, surveying, geodesy, security, position estimation etc.,

With the successful launch of the all seven satellites, it has become possible for the country to offer navigation services on its own for users in and around India with Position better than $20 \mathrm{~m}$ (Target:10 m) in the coverage area, Velocity $0.1 \mathrm{~m} / \mathrm{s}$ and Time to User better than 50 nanoseconds. In future the IRNSS Service may be extended to a service area bounded by $40^{\circ} \mathrm{S}$ to $50^{\circ} \mathrm{N}$ latitude $; 30^{\circ}$ to $130^{\circ} \mathrm{E}$ longitude.

\section{REFERENCES}

[1] A.S. Ganeshan. "Towards Self Reliance in Satellite based Navigation GAGAN and IRNSS," GNSS User Meet, 2015.

[2] Rajesh C. Mathur. "Global Navigation Satellite Systems - Powering Locational Intelligence in Enterprise geospatial Applications," GNSS User Meet, 2015

[3] A.D.Sharma, and A.Supraja Reddy. "Advantage IRNSS S-Band Signal for Precision Approach Using LAAS," GNSS User Meet, 2015

[4] O. Montenbruck, P. Steigenberger, and S. Riley. "IRNSS Orbit Determination and Broadcast Ephemeris Assessment," ION ITM, 2015.

[5] A.S. Ganeshan, S.C. Ratnakara, Nirmala Srinivasan, Babu Rajaram, Neethe Tirmal, and Karthik Anbalagan. "First Position Fix with IRNSS," ISRO, 2015. 